From the Department of Pediatrics and Division of Cancer Prevention and Control Research, David Geffen School of Medicine at University of CaliforniaLos Angeles (UCLA) and UCLA Jonsson Comprehensive Cancer Center, Los Angeles, CA; Dana Farber Cancer Institute, Boston, MA; School of Social Work, University of Michigan, Ann Arbor, Ml; Department of Psychology, University of Houston, Houston, TX; and Department of Epidemiology and Cancer Control, St Jude Children's Research Hospital, Memphis, TN.

Submitted November 18, 2008; accepted November 20, 2008, published online ahead of print at www.jco org on March 2, 2009.

Supported in part by Grant No. U24-CA55727 (L.L.R.) from the Nationa Cancer Institute; by the American Lebanese Syrian Associated Charities to St. Jude Children's Research Hospital; by postdoctoral fellowship from University of California-Los Angeles Jonsson Comprehensive Cancer Center (D.B.); and by Grant No. G-00-12-076-02 (L.Z.) from the Lance Armstrong Foundation

Authors' disclosures of potential conflicts of interest and author contributions are found at the end of this article.

Corresponding author: Lonnie K. Zeltzer MD, Dept of Pediatrics, David Geffen School of Medicine at University of California-Los Angeles, 22-464 MDCC, 10833 LeConte Ave, Los Angeles, CA 90095-1752; e-mail: Izeltzer@mednet .ucla.edu.

(c) 2009 by American Society of Clinical Oncology

0732-183X/09/2714-2396/\$20.00 DOI: 10.1200/JCO.2008.21.1433

\title{
Psychological Status in Childhood Cancer Survivors: A Report From the Childhood Cancer Survivor Study
}

Lonnie K. Zeltzer, Christopher Recklitis, David Buchbinder, Bradley Zebrack, Jacqueline Casillas, Jennie C.I. Tsao, Qian Lu, and Kevin Krull

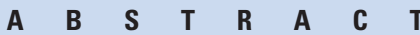

Psychological quality of life (QOL), health-related QOL (HROOL), and life satisfaction outcomes and their associated risk factors are reviewed for the large cohort of survivors and siblings in the Childhood Cancer Survivor Study (CCSS). This review includes previously published manuscripts that used CCSS data focused on psychological outcome measures, including the Brief Symptom Inventory (BSI-18), the Medical Outcomes Survey Short Form-36 (SF-36), the Cantril Ladder of Life, and other self-report questionnaires. Comparisons and contrasts are made between siblings and survivors, and to normative data when available, in light of demographic/health information and abstracted data from the medical record. These studies demonstrate that a significant proportion of survivors report more symptoms of global distress and poorer physical, but not emotional, domains of HRQOL. Other than brain tumor survivors, most survivors report both good present and expected future life satisfaction. Risk factors for psychological distress and poor HROOL are female sex, lower educational attainment, unmarried status, annual household income less than $\$ 20,000$, unemployment, lack of health insurance, presence of a major medical condition, and treatment with cranial radiation and/or surgery. Cranial irradiation impacted neurocognitive outcomes, especially in brain tumor survivors. Psychological distress also predicted poor health behaviors, including smoking, alcohol use, fatigue, and altered sleep. Psychological distress and pain predicted use of complementary and alternative medicine. Overall, most survivors are psychologically healthy and report satisfaction with their lives. However, certain groups of childhood cancer survivors are at high risk for psychological distress, neurocognitive dysfunction, and poor HRQOL, especially in physical domains. These findings suggest targeting interventions for groups at highest risk for adverse outcomes and examining the positive growth that remains despite the trauma of childhood cancer.

\section{J Clin Oncol 27:2396-2404. (C) 2009 by American Society of Clinical Oncology}

\section{INTRODUCTION}

Long-term follow-up of childhood cancer survivors provides unique opportunities to study psychological outcomes, as diagnosis and treatment take place during formative development of organ systems, cognition, emotions, and life experiences. On the basis of a median age at diagnosis of 6 years, survivors can expect to live another 66 years, ${ }^{1}$ and issues pertinent to quality of life (QOL) and emotions will vary across the adult age spectrum. Factors that impact educational attainment, employment, marriage and intimacy, fertility, and other life values differ in the emerging young adult compared with the older adult. ${ }^{2}$ These factors in adults who are childhood cancer survivors, along with delayed health sequelae for some, may explain the differing psychological outcomes reported in this population. Because of the vastness of salient potential risk factors, large cohorts of survivors are needed to examine the impact of specific diagnoses and treatments in relation to age, sex, other demographic factors, and physical health that can each and together impact long-term psychological outcomes.

A review of the literature on the psychosocial outcomes of childhood cancer survivors demonstrates varied, and sometimes contradictory, results. This inconsistency in outcomes is likely caused by small sample sizes, varied outcome measures used across studies, and selection of population norms for the comparison group. Studies in which survivors report no differences in psychological outcomes compared with those of population norms may be viewed as having been influenced by response bias. ${ }^{3}$ In addition, normative data with which survivors are compared in many studies have their own limitations, especially in terms of demographic characteristics of the control group that may be quite different from those in the survivor cohort that is 
studied. Siblings of long-term survivors may provide a better comparison group for psychological health outcomes, particularly given the similarities in ethnicity, culture, community, socioeconomic status, genetics, and family environment. Although subgroups of siblings may have their own set of psychological effects, such comparison data might at least provide a conservative estimate of risks for negative psychological sequelae, which would help to direct targeted intervention.

For reasons thus noted, the Childhood Cancer Survivor Study (CCSS) offers the opportunity to move beyond barriers not only to examine the psychological QOL and health-related QOL (HRQOL) of adult survivors of childhood cancer, but also to compare these outcomes to a matched cohort of adult siblings and to population norms. Additionally, by having diagnoses and treatment-documented data, as well as self-report data from standardized measures, the CCSS offers the opportunity to have a broad view on psychological QOL and HRQOL and to identify at-risk subgroups of survivors who may benefit from psychosocial intervention. This report provides an overview of the findings from the CCSS in relation to psychological outcomes, neurocognitive function, QOL, and life expectations. Specific recommendations for targeted interventions, disease prevention, and health promotion are suggested.

\section{REVIEW OF PSYCHOLOGICAL MEASURES IN CCSS}

\section{Brief Symptom Inventory-18}

The Brief Symptom Inventory-18 (BSI-18) measures psychological distress by using 18 items related to symptoms experienced during the previous 7 days. ${ }^{4}$ The BSI-18 has been validated in healthy volunteers, ${ }^{5}$ in cancer patients, ${ }^{4}$ and in the CCSS cohort of survivors. ${ }^{3}$ The BSI-18 has a summary scale, the global distress index, and three subscales: depression, anxiety, and somatization. Raw scores are converted to $\mathrm{T}$ scores on the basis of normative data. The $\mathrm{T}$ scores are then dichotomized, in which a $\mathrm{T}$ score $\geq 63$ classified a respondent as having psychological distress. ${ }^{3}$

\section{Medical Outcomes Short Form-36}

The Medical Outcomes Short Form-36 (SF-36) measures HRQOL by using 36 questions on general health, well-being, and QOL during the previous 4 weeks. ${ }^{6}$ The SF-36 has two summary scales and eight subscales that represent different aspects of well-being. ${ }^{6} \mathrm{Data}$ are presented as $\mathrm{T}$ scores with a mean score of 50 and a standard deviation (SD) of 10, in which a higher score indicates better HRQOL. ${ }^{7}$ T scores are dichotomized, in which a T score at least one $\mathrm{SD}$ below the population mean $(\leq 40)$ classified a respondent as having reported poor HRQOL. Reulen et $\mathrm{al}^{8}$ studied the psychometric properties of the SF-36 in more than 10,000 adult survivors of childhood cancer, which confirmed its validity and reliability for this population. ${ }^{8}$

\section{Cantril Ladder of Life}

The Ladder of Life (LOL) assesses respondents' life satisfaction with three self-report items that indicate life satisfaction in the past, present, and future. ${ }^{9}$ Ratings are made on a 10-point scale that ranges from best possible life to worst possible life, ${ }^{9}$ which provides a global rating of life satisfaction used previously in population studies and clinical samples of cancer survivors. ${ }^{10,11}$

\section{Childhood Cancer Survivor Study Neurocognitive Questionnaire}

The Childhood Cancer Survivor Study Neurocognitive Questionnaire (CCSS-NCQ) was developed and validated within the CCSS cohort as a neurocognitive measure specifically designed for cancer survivors. ${ }^{12}$ It was constructed to assess skills reported to be sensitive to the effects of radiation and/or antimetabolite chemotherapy and skills included in established measures of executive functioning. The CCSS-NCQ was developed by selecting a subset of items represented in an investigational version of the Brief Rating Inventory of Executive Function-Adult (BRIEF-A), to which additional items were added. ${ }^{13}$ Exploratory factor analysis in 382 siblings of cancer survivors revealed four factors that demonstrated good internal consistency: task efficiency (ie, initiating and completing tasks in a rapid manner), emotional regulation (ie, emotional reactivity and frustration tolerance), organization (ie, organization of the individual's environment), and memory (ie, working memory and long-term memory).

Construct and concurrent validities of the four CCSS-NCQ factors were demonstrated through correlation with factors from other established measures, including the Behavior Problem Index (BPI) and the BSI, respectively. ${ }^{4,14}$ The task efficiency factor from the CCSSNCQ was highly correlated with the BPI domain of attention deficits. In addition, the depression/anxiety domain from the BPI was correlated more strongly with the CCSS-NCQ emotional regulation factor. ${ }^{12}$ Similarly, this emotional regulation factor correlated more highly with the BSI factors than did any of the other CCSSNCQ factors.

Discriminant validity of the CCSS-NCQ was examined by comparing the factor scores between cancer survivors who were at high risk versus low risk for neurocognitive dysfunction. The high-risk groups were comprised of individuals who had a history of cerebrovascular stroke or epilepsy (ie, neurologic group $[n=172]$ ) or who received high-dose cranial radiation (ie, $\geq 35 \mathrm{~Gy}$; chemoradiotherapy group $[\mathrm{n}=247])$, whereas the low-risk group $(\mathrm{n}=688)$ included healthy survivors who had no history of central nervous system (CNS) disease, CNS treatment, or major organ complications or procedures. Compared with siblings, the high-risk groups demonstrated significantly increased rates of problems in task efficiency, memory, emotional regulation, and organization. ${ }^{12}$ Equally important is that the low-risk group of healthy survivors demonstrated no significant increase in problems compared with the sibling sample.

\section{PSYCHOLOGICAL HEALTH STATUS IN RELATION TO} CANCER DIAGNOSIS

Overall, childhood cancer survivors are relatively healthy, both physically and emotionally, compared with siblings. However, withingroup comparisons demonstrate that a significant subset of patients report impaired physical health status, poor psychological health, and low HRQOL. ${ }^{15,16}$ In reference to national norms, survivors are $80 \%$ more likely than their siblings to report clinically relevant impairment in mental health QOL (odds ratio [OR], 1.8; 95\% CI, 1.6 to 2.1), and greater than five times more likely to report functional impairment in HRQOL (OR, 5.2; 95\% CI, 4.1 to 6.6$).{ }^{15}$ In addition, survivors are twice as likely to report clinical levels of emotional distress compared with their siblings (OR, 2.2; 95\% CI, 1.8 to 2.8$).{ }^{15}$ Some of the important differences within cancer diagnostic groups are highlighted in this 
section, as are differences compared with siblings. One of the strengths of the CCSS cohort is the large sample size of long-term survivors, which can result in statistically significant differences when actual group differences are generally small. As such, emphasis in the survivor-type sections will be placed on comparisons of rates of clinically relevant impairment within diagnostic and/or treatment groups. In each instance, impairment is defined by scores that exceed established thresholds on validated clinical instruments. The section with a discussion of instruments explains specific threshold determinants. As an example, for the BSI-18, the clinical cutoff T score of $\geq 63$ was used to assess increased risk for any of the subscales (eg, depression, anxiety, or somatic distress).

\section{Leukemia Survivors}

Compared with siblings, leukemia survivors demonstrate elevated rates of psychological distress (OR, 2.1; 95\% CI, 1.6 to 2.7). ${ }^{16,17}$ During patient adolescence, parents report that leukemia survivors experience increased rates of depression and anxiety (response rate [RR], 1.6; 95\% CI, 1.2 to 2.2) and social-skills deficits (RR, 1.4; 95\% CI, 1.1 to 1.8 ) compared with sibling controls. ${ }^{18}$

\section{Brain Tumor Survivors}

Brain tumor survivors demonstrate higher rates of impaired physical health compared with siblings (OR, 3.5; 95\% CI, 2.7 to 4.4$)^{15}$ and compared with leukemia survivors. ${ }^{15,16,19}$ This impairment includes a lower capacity to fulfill physical roles as well as lower expectations of future life satisfaction. ${ }^{16}$ Additionally, survivors of astrocytomas report lower HRQOL within the mental health domain compared with siblings, which demonstrates the largest effect size with respect to impairment within this domain. ${ }^{16}$ Brain tumor survivors also endorse more psychological distress, including depression and somatization, ${ }^{16,20}$ and more symptoms of fatigue and daytime sleepiness (OR, 1.6; 95\% CI, 1.0 to 2.8$)^{21}$

\section{Neuroblastoma Survivors}

Neuroblastoma survivors do not report impaired physical health compared with leukemia or kidney tumor survivors but do report higher rates of psychological distress, including depression, somatization, and anxiety, compared with siblings. ${ }^{19,22}$ However, no differences in psychological distress have been found between neuroblastoma survivors and survivors of other solid tumors, including kidney tumor, bone tumor, or sarcoma. ${ }^{18}$

\section{Bone Tumor and Sarcoma Survivors}

Bone tumor and sarcoma survivors demonstrate higher rates of impaired physical health (OR, 2.6; 95\% CI, 2.0 to 3.4) and increased reports of pain compared with siblings, norms, and leukemia survivors. ${ }^{15,16,19}$ More specifically, osteosarcoma survivors demonstrate the largest effect size with respect to impaired physical functioning compared with siblings and norms. ${ }^{16}$ Both osteosarcoma and Ewing sarcoma survivors demonstrate the largest effect size with respect to bodily pain compared with siblings and norms. ${ }^{16}$ In addition, location of primary tumor site impacts these health outcomes. Pelvic tumors are associated with poorer outcomes compared with extremity tumors. ${ }^{23}$ Bone tumor survivors, but not survivors of other solid tumors (eg, kidney tumors, neuroblastoma), demonstrate more psychological distress, including anxiety (OR, 2.1; 95\% CI, 1.5 to 2.8$)$ and somatization (OR, 2.2; 95\% CI, 1.6 to 3.0 ) compared with siblings and popu- lation norms. ${ }^{16,18}$ Additionally, osteosarcoma survivors report lower mean scores on emotional role functioning and mental health domains compared with siblings. ${ }^{16}$ Sarcoma survivors also endorse more symptoms of sleep disruption (OR, 1.9; 95\% CI, 1.1 to 3.2) compared with siblings. ${ }^{21}$

\section{Wilms Tumor Survivors}

Wilms tumor survivors report higher rates of impaired general health compared with siblings (OR, 1.8; 95\% CI, 1.3 to 2.7 ), but no differences are found compared with leukemia or neuroblastoma survivors. ${ }^{15,16,22}$ In addition, no differences in psychological health are reported by Wilms tumor survivors compared with neuroblastoma, bone tumors, or other sarcoma survivors. ${ }^{18}$

\section{Lymphoma Survivors}

Lymphoma survivors report higher rates of psychological distress, including anxiety (OR, 1.8; 95\% CI, 1.3 to 2.6$)$ and somatization (OR, 1.9; 95\% CI, 1.3 to 2.6), compared with siblings and population norms. ${ }^{16}$ More specifically, survivors of Hodgkin's lymphoma report impaired physical health compared with leukemia survivors ${ }^{15,19}$ and more symptoms of somatization compared with leukemia and nonHodgkin's lymphoma survivors. ${ }^{24}$ With respect to somatization, Hodgkin's lymphoma survivors also demonstrate higher rates of clinically significant somatization compared with siblings (OR, 2.5; 95\% CI, 1.9 to 3.2). ${ }^{16}$ They also endorse more complaints of fatigue, sleep disruption, and daytime sleepiness compared with siblings. ${ }^{21}$ NonHodgkin's lymphoma survivors report lower vitality in assessment of their HRQOL scores compared with siblings and norms, which demonstrates the largest effect size with respect to impaired vitality. ${ }^{16}$

\section{PSYCHOLOGICAL HEALTH STATUS IN RELATION TO CANCER TREATMENT}

Treatments such as irradiation, chemotherapy, and surgical intervention may themselves exert long-term effects on survivors' psychological outcomes. Tables 1 and 2 present data on psychological distress (ie, BSI) and HRQOL (ie, SF-36) by treatment factors.

\section{Irradiation}

Irradiation is associated with psychological distress, including somatization, in survivors (Table 1). ${ }^{16}$ Solid tumor survivors exposed to irradiation-including those diagnosed with kidney tumors, neuroblastoma, bone tumors, and sarcomas - report more psychological distress, including somatization. ${ }^{18}$ Survivors treated with irradiation endorse more fatigue than those treated without irradiation, with the exception of survivors of Hodgkin's disease who are treated with mediastinal radiation therapy. ${ }^{21}$

Pelvic irradiation is associated with poorer HRQOL compared with nonirradiated cohorts. ${ }^{23}$ Kidney tumor survivors who had received pelvic irradiation report poorer emotional role functioning compared with those treated without irradiation. ${ }^{22}$

CNS irradiation is linked to impairment in physical health in survivors when compared with non-CNS-irradiated survivors (Table 2). ${ }^{15,16,19}$ Impairment includes poor general health, poor physical functioning, lower fulfillment of roles physically, more functional impairment, and more activity limitations. CNS-irradiated leukemia 


\begin{tabular}{|c|c|c|c|c|c|c|c|c|c|c|c|c|c|c|c|c|c|}
\hline \multirow[b]{3}{*}{ Variable } & \multirow{3}{*}{$\begin{array}{l}\text { Sample } \\
\text { Size } \\
\text { (n) }\end{array}$} & \multicolumn{16}{|c|}{ Scale Outcome } \\
\hline & & \multicolumn{4}{|c|}{ Depression } & \multicolumn{4}{|c|}{ Anxiety } & \multicolumn{4}{|c|}{ Somatization } & \multicolumn{4}{|c|}{ Global Status Index } \\
\hline & & No. & $\%$ & OR & $95 \% \mathrm{Cl}$ & No. & $\%$ & OR & $95 \% \mathrm{Cl}$ & No. & $\%$ & OR & $95 \% \mathrm{Cl}$ & No. & $\%$ & OR & $95 \% \mathrm{Cl}$ \\
\hline \multicolumn{18}{|l|}{ Sex } \\
\hline Male & 3,481 & 351 & 10.8 & - & & 206 & 6.3 & - & & 343 & 10.5 & - & & 278 & 8.5 & - & \\
\hline Female & 3,666 & 472 & 13.6 & 1.3 & 1.1 to 1.5 & 347 & 10.0 & 1.7 & 1.4 to 2.0 & 575 & 16.6 & 1.7 & 1.5 to 2.0 & 427 & 12.3 & 1.53 & 1.3 to 1.8 \\
\hline \multicolumn{18}{|l|}{$\begin{array}{l}\text { Age at diagnosis, } \\
\text { years }\end{array}$} \\
\hline $0-3$ & 2,211 & 261 & 12.5 & 1.0 & 0.8 to 1.2 & 184 & 8.8 & 1.1 & 0.8 to 1.4 & 248 & 11.9 & 0.8 & 0.6 to 0.9 & 222 & 10.6 & 1.1 & 0.8 to 1.4 \\
\hline $4-9$ & 2,137 & 251 & 12.6 & 1.0 & 0.8 to 1.2 & 170 & 8.5 & 1.1 & 0.8 to 1.5 & 277 & 13.9 & 0.9 & 0.7 to 1.1 & 219 & 11.0 & 1.1 & 0.9 to 1.4 \\
\hline $10-14$ & 1,497 & 160 & 11.3 & 0.9 & 0.7 to 1.1 & 103 & 7.3 & 0.9 & 0.7 to 1.2 & 204 & 14.5 & 1.0 & 0.8 to 1.2 & 141 & 10.0 & 1.0 & 0.8 to 1.3 \\
\hline $15-20$ & 1,302 & 151 & 12.2 & - & & 96 & 7.7 & - & & 189 & 15.2 & - & & 123 & 9.9 & - & \\
\hline \multicolumn{18}{|l|}{ Survival time, years } \\
\hline$<20$ & 1,985 & 243 & 12.9 & 1.0 & 0.8 to 1.3 & 171 & 9.1 & 1.1 & 0.8 to 1.6 & 249 & 13.2 & 0.8 & 0.7 to 1.1 & 207 & 11.0 & 0.9 & 0.7 to 1.2 \\
\hline $20-24$ & 2,432 & 280 & 11.8 & 0.9 & 0.7 to 1.2 & 195 & 8.2 & 1.0 & 0.8 to 1.4 & 311 & 13.1 & 0.8 & 0.6 to 1.0 & 222 & 9.3 & 0.7 & 0.6 to 1.0 \\
\hline $25-29$ & 1,829 & 207 & 12.1 & 1.0 & 0.7 to 1.2 & 129 & 7.5 & 1.0 & 0.7 to 1.3 & 239 & 13.9 & 0.9 & 0.7 to 1.1 & 185 & 10.8 & 0.9 & 0.7 to 1.1 \\
\hline$\geq 30$ & 801 & 93 & 12.3 & - & & 58 & 7.7 & - & & 119 & 15.8 & - & & 91 & 12.1 & - & \\
\hline \multicolumn{18}{|l|}{ Surgery } \\
\hline Yes & 5,403 & 652 & 12.1 & 1.1 & 0.9 to 1.4 & 435 & 8.1 & 1.1 & 0.8 to 1.4 & 733 & 13.6 & 1.0 & 0.8 to 1.2 & 566 & 10.5 & 1.2 & 0.9 to 1.5 \\
\hline No & 1,334 & 171 & 12.8 & - & & 118 & 8.8 & - & & 185 & 13.9 & - & & 139 & 10.4 & - & \\
\hline \multicolumn{18}{|l|}{ Chemotherapy } \\
\hline Yes & 5,326 & 646 & 12.1 & 1.0 & 0.8 to 1.2 & 450 & 8.4 & 1.2 & 0.9 to 1.5 & 736 & 13.8 & 1.1 & 0.9 to 1.4 & 565 & 10.6 & 1.1 & 0.9 to 1.4 \\
\hline No & 1,411 & 177 & 12.5 & - & & 103 & 7.3 & - & & 182 & 12.9 & - & & 140 & 9.9 & - & \\
\hline \multicolumn{18}{|l|}{ Radiation } \\
\hline Cranial & 2,057 & 287 & 14.0 & 1.2 & 1.0 to 1.5 & 159 & 7.7 & 0.9 & 0.7 to 1.1 & 275 & 13.4 & 1.1 & 1.0 to 1.4 & 214 & 10.4 & 1.0 & 0.8 to 1.2 \\
\hline Other than cranial & 2,415 & 264 & 10.9 & 0.9 & 0.7 to 1.1 & 189 & 7.8 & 0.9 & 0.7 to 1.1 & 372 & 15.4 & 1.3 & 1.1 to 1.5 & 251 & 10.4 & 1.0 & 0.8 to 1.2 \\
\hline None & 2,265 & 272 & 12.0 & - & & 205 & 9.1 & - & & 271 & 12.0 & - & & 240 & 10.6 & - & \\
\hline
\end{tabular}

NOTE. Models adjusted for all variables in left column of the table. Odds ratios and $95 \%$ confidence intervals compared poor outcomes by treatment variables. Abbreviations: BSI, Brief Symptom Inventory; OR, odds ratio.

survivors report no differences in fatigue, sleep disruption, or daytime sleepiness, ${ }^{21}$ although they report more functional limitations. ${ }^{17}$

In contrast to leukemia survivors, brain tumor survivors do not link treatment effects to psychological distress, whether predictors are the examination of brain radiation dosage or the use of concomitant chemotherapy. ${ }^{20}$ One explanation for this finding may be that the impact of the location and invasion of the brain tumor itself might be more salient than specific treatments. For brain tumor survivors who had received CNS irradiation, there is an increase in sleep disruption. ${ }^{21}$

\section{Surgical Therapy}

Surgical therapy is associated with impairment in physical health (Table 2) ${ }^{15}$; yet, in bone tumor survivors, no differences were noted in recipients of amputation versus recipients of limb-sparing procedures in both overall functioning and HRQOL. ${ }^{23}$ Interestingly, amputees report less functional impairment and lower levels of anxiety and somatization compared with nonamputees. ${ }^{18,23}$ Although limbsparing procedures originally were intended to provide better psychological outcomes and function, a study in 1982, in fact, found no difference in QOL in extremity sarcoma patients who underwent amputation or limb-sparing procedures. ${ }^{25}$

\section{Chemotherapy}

Chemotherapy exposures, including alkylating agents and anthracyclines, are associated with an increase in physical impairment and psychological distress, including anxiety. ${ }^{15}$ Survivors of leukemia and lymphoma exposed to intensive chemotherapy report more psychological distress, including depression and somatization..$^{24}$ Among survivors of neuroblastoma, kidney tumors, bone tumors, and sarcomas, exposure to alkylators also is associated with more psychological distress, including depression. ${ }^{18}$

\section{NEUROCOGNITIVE OUTCOMES}

Neurocognitive dysfunction is demonstrated in up to $40 \%$ of childhood cancer survivors in one or more specific domains (eg, processing speed, attention, memory). ${ }^{26,27}$ Impairment in these domains can impede the ability to learn new information, and the maintenance of previously learned information, and ultimately can lead to declines in global intellect. ${ }^{28}$ This, in turn, can result in poor academic and vocational success, low self-esteem, and behavioral or emotional disorders.

Attention problems have been reported in adolescents who are long-term survivors of childhood cancer. In a comparison of 2,979 survivors and 649 siblings between 12 and 17 years of age, Schultz et $\mathrm{al}^{18}$ reported that survivors were more likely to demonstrate attention problems on the basis of parent report (RR, 1.4; 95\% CI, 1.1 to 1.9). In particular, compared with siblings, elevated rates of attention problems were reported in survivors of leukemia (RR, 1.5; 95\% CI, 1.2 to 2.0) and CNS tumors (RR, 1.8; 95\% CI, 1.2 to 2.5). In addition, such problems were more common in patients treated with cranial radiation alone (RR, $1.8 ; 95 \% \mathrm{CI}, 1.2$ to 2.6$)$ or when combined with 


\begin{tabular}{|c|c|c|c|c|c|c|c|c|c|c|c|c|c|c|c|c|c|c|c|c|c|}
\hline \multirow[b]{2}{*}{ Variable } & \multirow{2}{*}{$\begin{array}{l}\text { Sample } \\
\text { Size (n) }\end{array}$} & \multicolumn{4}{|c|}{ Physical Function } & \multicolumn{4}{|c|}{ Physical Role } & \multicolumn{4}{|c|}{ Bodily Pain } & \multicolumn{4}{|c|}{ General Health } & \multicolumn{4}{|c|}{ Vitality } \\
\hline & & No. & $\%$ & OR & $95 \% \mathrm{Cl}$ & No. & $\%$ & OR & $95 \% \mathrm{Cl}$ & No. & $\%$ & OR & $95 \% \mathrm{Cl}$ & No. & $\%$ & OR & $95 \% \mathrm{Cl}$ & No. & $\%$ & OR & $95 \% \mathrm{Cl}$ \\
\hline \multicolumn{22}{|l|}{ Sex } \\
\hline Male & 3,481 & 292 & 8.9 & - & & 549 & 16.8 & - & & 346 & 10.6 & - & & 511 & 15.7 & - & & 1,031 & 31.6 & - & \\
\hline Female & 3,666 & 457 & 13.2 & 1.7 & 1.4 to 2.0 & 791 & 22.8 & 1.5 & 1.3 to 1.7 & 539 & 15.5 & 1.6 & 1.4 to 1.8 & 794 & 22.9 & 1.6 & 1.4 to 1.9 & 1,653 & 47.6 & 2.0 & 1.8 to 2.2 \\
\hline \multicolumn{22}{|c|}{$\begin{array}{l}\text { Age at diagnosis, } \\
\text { years }\end{array}$} \\
\hline $0-3$ & 2,211 & 171 & 8.2 & 0.5 & 0.4 to 0.6 & 323 & 15.5 & 0.5 & 0.4 to 0.7 & 217 & 10.4 & 0.5 & 0.4 to 0.7 & 346 & 16.6 & 0.6 & 0.5 to 0.8 & 790 & 37.8 & 0.9 & 0.8 to 1.0 \\
\hline $4-9$ & 2,137 & 189 & 9.5 & 0.5 & 0.4 to 0.7 & 374 & 18.7 & 0.7 & 0.6 to 0.8 & 232 & 11.6 & 0.6 & 0.5 to 0.8 & 362 & 18.1 & 0.7 & 0.6 to 0.9 & 785 & 39.3 & 1.0 & 0.8 to 1.1 \\
\hline $10-14$ & 1,497 & 188 & 13.3 & 0.8 & 0.6 to 1.0 & 330 & 23.4 & 0.9 & 0.7 to 1.1 & 221 & 15.7 & 0.9 & 0.7 to 1.0 & 292 & 20.7 & 0.8 & 0.7 to 1.0 & 607 & 43.0 & 1.1 & 1.0 to 1.3 \\
\hline $15-20$ & 1,302 & 201 & 16.2 & - & & 313 & 25.2 & & & 215 & 17.3 & - & & 305 & 24.6 & - & & 502 & 40.5 & - & \\
\hline \multicolumn{22}{|l|}{$\begin{array}{l}\text { Survival time, } \\
\text { years }\end{array}$} \\
\hline$<20$ & 1,985 & 164 & 8.7 & 0.5 & 0.4 to 0.7 & 340 & 18.0 & 0.7 & 0.6 to 0.9 & 225 & 11.9 & 0.7 & 0.5 to 0.9 & 322 & 17.1 & 0.6 & 0.5 to 0.8 & 723 & 38.3 & 0.9 & 0.8 to 1.1 \\
\hline $20-24$ & 2,432 & 247 & 10.4 & 0.6 & 0.5 to 0.8 & 456 & 19.1 & 0.8 & 0.6 to 0.9 & 290 & 12.2 & 0.7 & 0.5 to 0.9 & 448 & 18.8 & 0.7 & 0.6 to 0.8 & 937 & 39.3 & 1.0 & 0.8 to 1.1 \\
\hline $25-29$ & 1,829 & 223 & 13.0 & 0.8 & 0.6 to 1.0 & 364 & 21.2 & 0.8 & 0.7 to 1.0 & 243 & 14.2 & 0.8 & 0.6 to 1.0 & 338 & 19.7 & 0.7 & 0.6 to 0.8 & 717 & 41.8 & 1.0 & 0.9 to 1.3 \\
\hline$\geq 30$ & 801 & 115 & 15.2 & - & & 180 & 23.8 & - & & 127 & 16.8 & - & & 197 & 26.1 & - & & 307 & 40.7 & & \\
\hline \multicolumn{22}{|l|}{ Surgery } \\
\hline Yes & 5,403 & 653 & 12.1 & 1.9 & 1.5 to 2.5 & 1106 & 20.5 & 1.2 & 1.0 to 1.5 & 726 & 13.4 & 1.2 & 1.0 to 1.4 & 1063 & 19.7 & 1.1 & 0.9 to 1.3 & 2149 & 39.8 & 1.1 & 1.0 to 1.3 \\
\hline No & 1,334 & 96 & 7.2 & - & & 234 & 17.5 & - & & 159 & 11.9 & - & & 242 & 18.1 & - & & 535 & 40.1 & - & \\
\hline \multicolumn{22}{|l|}{ Chemotherapy } \\
\hline Yes & 5,326 & 565 & 10.6 & 1.0 & 0.9 to 1.2 & 1033 & 19.4 & 1.0 & 0.8 to 1.1 & 696 & 13.1 & 1.1 & 0.9 to 1.4 & 1,036 & 19.5 & 1.1 & 1.0 to 1.6 & 2,093 & 39.3 & 0.9 & 0.8 to 1.1 \\
\hline No & 1,411 & 184 & 13.0 & - & & 307 & 21.8 & - & & 189 & 13.4 & - & & 269 & 19.1 & - & & 591 & 41.9 & - & \\
\hline \multicolumn{22}{|l|}{ Radiation } \\
\hline Cranial & 2,057 & 239 & 11.6 & 1.3 & 1.1 to 1.6 & 434 & 21.1 & 1.4 & 1.2 to 1.6 & 263 & 12.8 & 1.1 & 0.9 to 1.3 & 387 & 18.8 & 1.3 & 1.1 to 1.6 & 872 & 42.4 & 1.1 & 1.0 to 1.3 \\
\hline $\begin{array}{l}\text { Other than } \\
\text { cranial }\end{array}$ & 2,415 & 281 & 11.6 & 0.9 & 0.7 to 1.1 & 523 & 21.7 & 1.2 & 1.0 to 1.4 & 345 & 14.3 & 1.0 & 0.9 to 1.2 & 572 & 23.7 & 1.6 & 1.3 to 1.8 & 981 & 40.6 & 1.1 & 0.9 to 1.2 \\
\hline None & 2,265 & 229 & 10.1 & - & & 383 & 16.9 & - & & 277 & 12.2 & - & & 346 & 15.3 & - & & 831 & 36.7 & - & \\
\hline & Sample & & $\begin{array}{r}\text { Emc } \\
\mathrm{R}\end{array}$ & $\begin{array}{l}\text { otional } \\
\text { Role } \\
\end{array}$ & & & & $\begin{array}{l}\text { Social } \\
\text { unction }\end{array}$ & & & & $\begin{array}{l}\text { Mental } \\
\text { Health }\end{array}$ & & & $\begin{array}{r}\mathrm{Ph} \\
\text { Com } \\
\text { Sur } \\
\end{array}$ & $\begin{array}{l}\text { hysical } \\
\text { mponer } \\
\text { Immary }\end{array}$ & & & $\begin{array}{r}\mathrm{Me} \\
\text { Comp } \\
\text { Sum } \\
\end{array}$ & $\begin{array}{l}\text { ental } \\
\text { ponen } \\
\text { nmary }\end{array}$ & \\
\hline Variable & Size (n) & No. & $\%$ & OR & $95 \% \mathrm{Cl}$ & No. & $\%$ & OR & $95 \% \mathrm{Cl}$ & No. & $\%$ & OR & $95 \% \mathrm{Cl}$ & No. & $\%$ & OR & $95 \% \mathrm{Cl}$ & No. & $\%$ & $\mathrm{OR}$ & $95 \% \mathrm{Cl}$ \\
\hline Sex & & & & & & & & & & & & & & & & & & & & & \\
\hline Male & 3,481 & 505 & 15.5 & - & & 408 & 12.5 & - & & 244 & 7.5 & - & & 422 & 12.9 & - & & 556 & 17.0 & - & \\
\hline Female & 3,666 & 763 & 22.0 & 1.6 & 1.4 to 1.8 & 600 & 17.3 & 1.5 & 1.3 to 1.7 & 352 & 10.1 & 1.41 & 1.2 to 1.7 & 646 & 18.6 & 1.6 & 1.4 to 1.9 & 802 & 23.1 & 1.5 & 1.3 to 1.7 \\
\hline $\begin{array}{c}\text { Age at diagno } \\
\text { years }\end{array}$ & & & & & & & & & & & & & & & & & & & & & \\
\hline $0-3$ & 2,211 & 397 & 19.0 & 1.0 & 0.9 to 1.3 & 320 & 15.3 & 1.0 & 0.8 to 1.3 & 201 & 9.6 & 1.20 & 0.9 to 1.6 & 239 & 11.4 & 0.4 & 0.3 to 0.5 & 436 & 20.9 & 1.2 & 1.0 to 1.5 \\
\hline $4-9$ & 2,137 & 378 & 18.9 & 1.1 & 0.9 to 1.3 & 289 & 14.5 & 1.0 & 0.8 to 1.2 & 182 & 9.1 & $1.2 \mathrm{c}$ & 0.9 to 1.5 & 272 & 13.6 & 0.5 & 0.4 to 0.6 & 415 & 20.8 & 1.2 & 1.0 to 1.5 \\
\hline $10-14$ & 1,497 & 266 & 18.9 & 1.0 & 0.9 to 1.3 & 213 & 15.1 & 1.0 & 0.8 to 1.2 & 118 & 8.4 & $1.1 \mathrm{C}$ & 0.8 to 1.4 & 266 & 18.9 & 0.7 & 0.7 to 0.9 & 283 & 20.1 & 1.2 & 1.0 to 1.4 \\
\hline $15-20$ & 1,302 & 227 & 18.3 & - & & 186 & 15.0 & - & & 95 & 7.7 & - & & 291 & 23.5 & - & & 224 & 18.1 & - & \\
\hline $\begin{array}{c}\text { Survival time, } \\
\text { years }\end{array}$ & & & & & & & & & & & & & & & & & & & & & \\
\hline$<20$ & 1,985 & 356 & 18.9 & 0.9 & 0.7 to 1.2 & 277 & 14.7 & 0.9 & 0.7 to 1.1 & 173 & 9.2 & $0.9 c$ & 0.7 to 1.2 & 235 & 12.5 & 0.5 & 0.4 to 0.6 & 379 & 20.1 & 1.2 & 1.0 to 1.5 \\
\hline $20-24$ & 2,432 & 437 & 18.3 & 0.9 & 0.7 to 1.1 & 331 & 13.9 & 0.8 & 0.6 to 1.0 & 192 & 8.1 & 0.8 & 0.6 to 1.1 & 356 & 14.9 & 0.7 & 0.6 to 0.9 & 478 & 20.1 & 1.2 & 1.0 to 1.5 \\
\hline $25-29$ & 1,829 & 325 & 19.0 & 0.9 & 0.8 to 1.2 & 272 & 15.9 & 0.9 & 0.7 to 1.2 & 159 & 9.3 & $1.0 \mathrm{C}$ & 0.7 to 1.3 & 306 & 17.9 & 0.7 & 0.6 to 0.9 & 355 & 20.7 & 1.2 & 1.0 to 1.4 \\
\hline$\geq 30$ & 801 & 150 & 19.9 & - & & 128 & 17.0 & - & & 72 & 9.5 & - & & 1712 & 22.6 & - & & 146 & 19.3 & - & \\
\hline Surgery & & & & & & & & & & & & & & & & & & & & & \\
\hline Yes & 5,403 & 1024 & 19.0 & 1.2 & 1.0 to 1.4 & 821 & 15.2 & 1.2 & 1.0 to 1.5 & 472 & 8.7 & $1.1 \mathrm{c}$ & 0.9 to 1.4 & 906 & 16.8 & 1.5 & 1.2 to 1.8 & 1,097 & 20.3 & 1.2 & 1.0 to 1.4 \\
\hline No & 1,334 & 244 & 18.3 & - & & 187 & 14.0 & - & & 124 & 9.3 & - & & 162 & 12.1 & - & & 261 & 19.6 & - & \\
\hline Chemotherap & & & & & & & & & & & & & & & & & & & & & \\
\hline Yes & 5,326 & 1001 & 18.8 & 1.0 & 0.9 to 1.2 & 785 & 14.7 & 1.0 & 0.8 to 1.1 & 480 & 9.0 & $1.1 \mathrm{c}$ & 0.9 to 1.4 & 821 & 15.4 & 1.1 & 0.9 to 1.3 & 1,071 & 20.1 & 1.0 & 0.9 to 1.2 \\
\hline No & 1,411 & 267 & 18.9 & - & & 223 & 15.8 & - & & 116 & 8.2 & & & 247 & 17.5 & - & & 287 & 20.3 & - & \\
\hline Radiation & & & & & & & & & & & & & & & & & & & & & \\
\hline Cranial & 2,057 & 381 & 18.5 & 1.0 & 0.8 to 1.1 & 318 & 15.5 & 1.1 & 1.0 to 1.4 & 186 & 9.0 & $1.0 \mathrm{c}$ & 0.8 to 1.2 & 330 & 16.0 & 1.4 & 1.2 to 1.6 & 400 & 19.4 & 0.9 & 0.8 to 1.1 \\
\hline $\begin{array}{l}\text { Other than } \\
\text { cranial }\end{array}$ & 2,415 & 447 & 18.5 & 0.9 & 0.8 to 1.1 & 364 & 15.1 & 1.0 & 0.9 to 1.2 & 200 & 8.3 & 0.9 & 0.7 to 1.1 & 438 & 18.1 & 1.1 & 1.0 to 1.4 & 481 & 19.9 & 0.9 & 0.8 to 1.1 \\
\hline None & 2,265 & 440 & 19.4 & - & & 326 & 14.4 & - & & 210 & 9.3 & - & & 300 & 13.2 & - & & 477 & 21.1 & - & \\
\hline
\end{tabular}

NOTE. Models adjusted for all variables in left column of the table. Odds ratios and $95 \%$ confidence intervals compared poor outcomes by treatment variables. Abbreviations: SF-36, Medical Outcomes Survey Short Form-36; OR, odds ratio. 
intrathecal methotrexate (RR, 1.6; 95\% CI, 1.2 to 1.6) compared with those survivors who were not receiving CNS treatment.

Neurocognitive problems have been reported to extend into adulthood for long-term survivors of childhood cancer. In an examination of functional limitations in 7,147 adult survivors, Ness et $\mathrm{al}^{19}$ indicated that $14 \%$ of survivors reported impairment in executive functioning (ie, abilities required for the planning, implementing, monitoring, and adaptation of behavior for success in one's environment). In addition, in a comparison of healthy survivors who received no CNS treatment and the siblings of survivors, those survivors who received high-dose cranial radiation to frontal areas of their brains (ie, $\geq 35$ Gy) reported significantly more problems with attention and processing speed, memory, and emotional regulation (Table 3). ${ }^{12}$ Thus, neurocognitive problems appear prevalent in this cohort, particularly for those treated with cranial radiation when measured by the CCSS-NCQ. See the Childhood Cancer Survivor Study Neurocognitive Questionnaire section for review of the validation process of this new instrument. The specific treatment factors that lead to increased neurocognitive problems, and the functional consequences of these problems, are yet to be determined. In addition, although the validity of self-reported ratings of neurocognitive impairment has been previously demonstrated, ${ }^{29}$ data collection currently is ongoing to compare the CCSS-NCQ to formal neuropsychological testing.

\section{PSYCHOLOGICAL FUNCTION AND HEALTH BEHAVIORS}

Psychological functioning appears related to health behaviors in longterm survivors of childhood cancer. In an examination of smoking behavior in survivors, Emmons et $\mathrm{al}^{30}$ reported that $28 \%$ of survivors had a history of being a smoker and that $17 \%$ were current smokers at the time of long-term follow-up. Predictors of smoking initiation include a household income less than $\$ 20,000$ (RR, 1.6; 95\% CI, 1.3 to 1.8) and less than a high school education (RR, 2.8; 95\% CI, 2.3 to 3.3). A reduced risk of smoking initiation was related to cancer diagnosis before 10 years of age (RR, $0.81 ; 95 \% \mathrm{CI}, 0.72$ to 0.91 ), receipt of pulmonary-toxic treatment ( $\mathrm{RR}, 0.88 ; 95 \% \mathrm{CI}, 0.79$ to 0.98$)$, and receipt of brain radiation ( $\mathrm{RR}, 0.61 ; 95 \% \mathrm{CI}, 0.53$ to 0.69$)$. In a follow-up study in which the survivors identified as current smokers, the number of cigarettes smoked was related to older age at diagnosis, lower educational attainment, and increased total emotional distress, as measured by the BSI. ${ }^{30}$
Alcohol use has also been examined in long-term survivors of childhood cancer. Lown et $\mathrm{al}^{31}$ examined alcohol consumption patterns in 10,398 survivors and 3,034 of their siblings. Drinking behavior was also compared with 4,774 individuals from the National Alcohol Survey. ${ }^{32}$ Compared with the siblings, survivors were less likely to be current drinkers (OR, 0.6; 95\% CI, 0.5 to 0.6 ) and were less likely to be risky or heavy drinkers (OR, $0.7 ; 95 \% \mathrm{CI}, 0.6$ to 0.8$).{ }^{31}$ Among those survivors who did report drinking, heavy drinking was more likely in those who reported poor health (OR, 1.5; 95\% CI, 1.1 to 1.9$)$, depression (OR, 1.7; 95\% CI, 1.4 to 2.2 ), anxiety (OR, 1.4; 95\% CI, 1.1 to 1.9 ), and somatic distress (OR, 1.7; 95\% CI, 1.2 to 2.2). Compared with survivors of leukemia, survivors of Wilms tumor had greater reports of heavy drinking (OR, 1.5; 95\% CI, 1.1 to 2.1), neuroblastoma (OR, $1.6 ; 95 \% \mathrm{CI}, 1.1$ to 2.3 ), and bone cancers (OR, $1.7 ; 95 \% \mathrm{CI}, 1.2$ to 2.2 ).

Thus, emotional distress is related to health behaviors in longterm survivors. Specifically, smoking initiation is higher in survivors with low socioeconomic status, who themselves are at increased risk for emotional distress. It is not surprising, therefore, to find that the degree of emotional distress is related to the intensity of smoking behavior. Such distress is also related to the intensity of alcohol consumption in current drinkers.

\section{RELATIONSHIP BETWEEN PHYSICAL HEALTH AND PSYCHOLOGICAL STATUS}

Chronic health conditions have been associated with psychological outcomes. In a comparison of 1,101 survivors of CNS tumors, Zebrack et $\mathrm{al}^{20}$ reported a correlation between health status and psychological functioning. Those survivors who rated their own health as poor also reported significantly more symptoms of depression, anxiety, and somatic distress. In addition, experience of a major medical condition within the past 2 years was related to the degree of reported somatic distress. Zeltzer et $\mathrm{al}^{16}$ reported a similar association in a larger group of cancer survivors. When 7,147 survivors of various cancer diagnoses were compared with 388 sibling controls, those survivors with a history of a major medical condition reported more symptoms of depression (OR, 1.2; 95\% CI, 1.0 to 1.4 ), anxiety (OR, 1.2; 95\% CI, 1.0 to 1.6$)$, and somatic distress (OR, $1.3 ; 95 \% \mathrm{CI}, 1.1$ to 1.6$)$.

Poor health also has been associated with self-reported QOL. Nagarajan et $\mathrm{al}^{23}$ examined HRQOL in 528 survivors of lowerextremity osteosarcoma and Ewing sarcoma. Of these survivors, 9.7\%

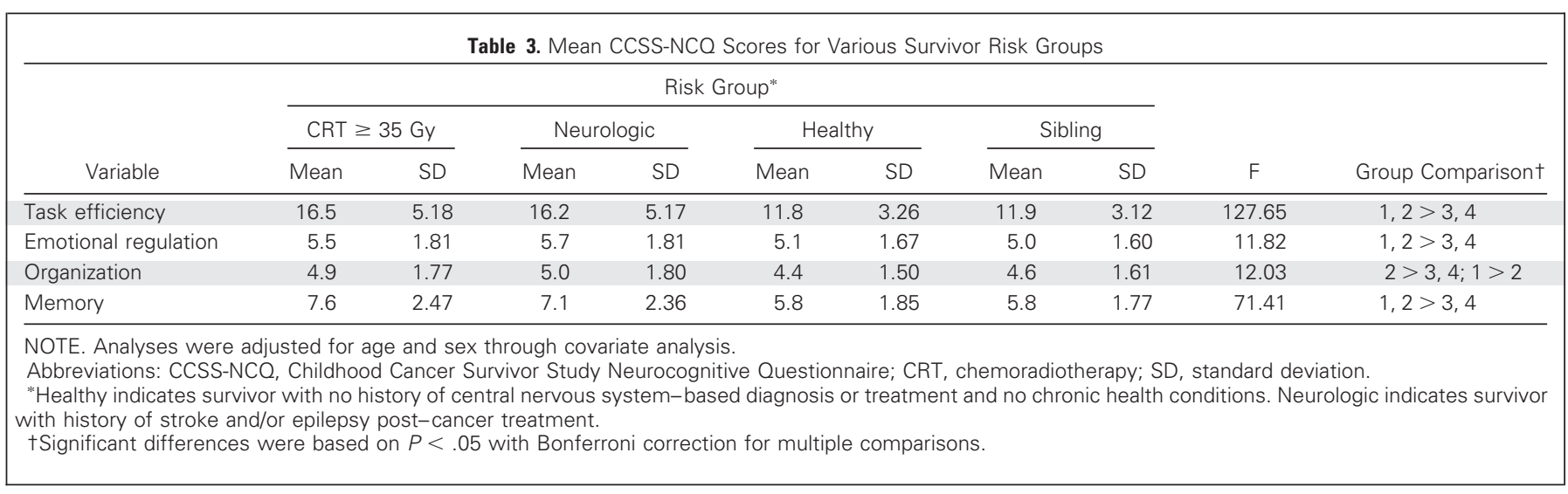


reported experiencing poor health. In this study, HRQOL was evaluated in areas of physical, psychological, social, and spiritual functioning. Poor health was significantly related to reduced QOL (OR, 7.5; $95 \%$ CI, 3.7 to 15.2 ). In a related study, Ness et $\mathrm{al}^{19}$ examined the association between physical mobility and emotional outcomes. When this relation was compared in 7,147 survivors of various cancer diagnoses, these investigators demonstrated a link between limitations in physical performance and emotional QOL. Specifically, those patients with limitations in physical mobility more often reported emotional problems that additionally limited their functioning (OR, 1.5; $95 \%$ CI, 1.3 to 1.8$)$.

Sleep quality and fatigue also have been examined in long-term survivors. In a comparison of 1,897 long-term survivors of childhood cancer with 369 of their siblings, Mulrooney et $\mathrm{al}^{21}$ reported that survivors were significantly more fatigued than their sibling controls (OR, 1.9; 95\% CI, 1.3 to 2.9 ). ${ }^{21}$ However, no significant group differences were reported for the presence of sleep disorders (OR, 1.4; 95\% CI, 0.9 to 1.9 ) or daytime sleepiness (OR, 1.0; 95\% CI, 0.7 to 1.4 ). Within the group of survivors, increased fatigue was related to depression (OR, 7.5; 95\% CI, 5.1 to 10.9) and being unmarried (OR, 2.7; 95\% $\mathrm{CI}, 2.0$ to 3.6). The presence of depression was also associated with the report of more sleep disorders (OR, 4.4; 95\% CI, 3.1 to 6.3 ) and of increased daytime sleepiness (OR, 3.4; 95\% CI, 2.3 to 5.0). Interestingly, the presence of congestive heart failure was also independently related to increased fatigue (OR, 2.9; 95\% CI, 1.4 to 6.1), sleep disorders (OR, 4.0; 95\% CI, 2.0 to 8.0), and increased daytime sleepiness (OR, 4.2; 95\% CI, 2.0 to 8.7 ).

Thus, in addition to the direct role of cancer diagnosis and specific treatments, the subsequent role of recovery and chronic health conditions, and fatigue and sleep, can impact psychological functioning and adjustment in the long-term survivor.

\section{FUTURE DIRECTIONS: IMPLICATIONS FOR INTERVENTION}

Although the contributions made by the CCSS to the study of psychosocial outcomes of childhood cancer survivors have been significant, the ultimate goal for better understanding of these outcomes must be to develop interventions to improve them. An expressed goal of psychosocial oncology research and intervention is to facilitate patients' and family members' adjustment to the short- and long-term consequences of treatment, recovery, and survivorship. ${ }^{33}$ Studies of psychological outcomes in the CCSS cohort indicate that childhood cancer confers some increased risk of problems in psychosocial adaptation, even many years after completion of therapy. Although most individual survivors can expect to achieve positive psychosocial adjustment and life satisfaction in adulthood, many survivors will experience limitations in social and psychological well-being. Moreover, many survivors, even those apparently doing quite well on distress scales, may continue to have concerns related to their treatment-including concerns about their physical health, body image, or selfconcept, access to life and health insurance, jobs and career options, and continued care from a skilled and attentive medical system. ${ }^{34-36}$ By reporting on the long-term psychosocial outcomes of childhood cancer survivors, reports from the CCSS can identify the significant areas of difficulty these survivors experience and can identify the groups of vulnerable survivors who are at greatest risk for poor outcomes.
Findings from the CCSS indicate that fatigue and psychological distress, including symptoms of depression and anxiety, are significant issues for a subgroup of adult survivors of childhood cancers, particularly among those who are women, are unemployed, have low income levels, and are struggling with late or delayed effects of cancer therapy. This finding is similar to that reported in studies of survivors of adult cancers, in which many adults are psychologically healthy but in which younger adults and those more heavily treated, such as those in a bone marrow transplant group, show the most pronounced psychological effects. ${ }^{37-39}$ These findings in both adult and childhood cancer survivors suggest that a subgroup of long-term survivors may benefit from psychological assessments and targeted interventions as part of long-term follow-up care. The caveat in the QOL and psychological outcome findings from the CCSS is the issue of clinical versus statistical significance. Clearly, studies that involve a large cohort may be overpowered to provide statistical significance in many domains. In the CCSS, siblings were used as a closer-matched control group than just normative data for comparisons. Although there are some areas in which siblings might indicate more problems than the general population, such survivor-sibling comparisons would make significant differences clinically meaningful and conservative. In this series of studies, normative data were also used for comparisons, when available, and risk estimates were made by using clinically significant cutoff scores, such as $\mathrm{T} \geq 63$ for the subscales of the BSI-18. The issue of clinical versus statistical significance in the assessment of QOL is discussed by Cella et al. ${ }^{40}$

Ideally, late psychological effects in survivors would be prevented best during childhood cancer treatment. Clinic-based family interventions have shown efficacy in the promotion of psychological adaptation and reduction of distress in pediatric cancer patients. ${ }^{41}$ Continued research of these interventions will lead to better understanding of their potential to affect long-term adjustment. In addition to interventions aimed at the prevention of long-term adjustment problems, research also needs to focus on addressing these concerns when they develop in childhood cancer survivors. Psychological interventions to help survivors of adult cancers cope with anxiety and depression have been developed, ${ }^{42-44}$ and adaptation of these programs for survivors of childhood cancers may be a promising strategy to pursue. Interventions to address fatigue in childhood cancer survivors may similarly benefit from research on adult survivors. ${ }^{45,46}$ Such interventions will need to address the potential contribution of medical factors (eg, endocrine, metabolic, cardiac, neurologic). Adaptation of existing exercise and other lifestyle interventions developed to reduce fatigue in other cancer populations should be a priority for research in the childhood cancer survivor population.

Survivors with medical morbidities and poor overall health were identified in several CCSS studies as having increased risk for poor psychosocial adaptation. These results indicate that intervention for these survivors will need to target several aspects of cancer therapy and aftercare. Pediatric oncology research continues to focus on decreasing toxicity of therapies, and these findings have the potential to succeed at primary prevention for these medical late-effects of treatment. ${ }^{47}$ Secondary and tertiary prevention of the psychosocial consequences of these morbidities may be realized by interventions that help survivors optimize their medical care for their conditions as well as interventions aimed at helping them cope more effectively with the burden of illness. Several programs for patient education, decision 
support, and positive coping have been developed for other aspects of cancer care ${ }^{48,49}$ and other diseases, ${ }^{50,51}$ and research should now focus on adapting these approaches to survivors of childhood cancer who face similar medical problems_-including pain and limitations in daily living, such as limited mobility.

Results from the CCSS clearly identify brain tumor survivors as a particularly vulnerable group, whose members report more psychological distress, fatigue, cognitive problems, and diminished life satisfaction. Neuropsychological problems seen in these survivors, and, to a lesser extent in survivors of other diseases who also received cranial radiation, have been previously characterized, ${ }^{52,53}$ but CCSS findings demonstrate the ongoing difficulties faced by these survivors and the associated risk for psychological problems. Targets of intervention for these survivors should include ongoing efforts to reduce toxicities of therapy as well as interventions aimed at helping these survivors receive the specialized cognitive, educational, and vocational services they require. Several clinical programs that address these survivor needs have been developed, ${ }^{54,55}$ but more research is needed to evaluate their effectiveness. Intervention addressed at public policymakers to ensure the availability of special education programs for patients who miss school or who have cognitive and emotional disabilities should be encouraged. Policies that ensure nondiscrimination in survivors' access to advanced educational opportunities and nondiscrimination in employment should be encouraged also. Cognitive remediation trials aimed at helping survivors improve their cognitive abilities have reported some positive results, ${ }^{56}$ and future research in this area is particularly promising. In several of the CCSS reports, limited educational achievement and lower income were associated with a variety of psychosocial problems, which highlights the need to make interventions that promote cognitive functioning and educational achievement priority areas.

In addition to identifying the priority areas for psychosocial intervention research with childhood cancer survivors, the CCSS itself can be used for development and evaluation of interventions for these survivors. Because of its large and representative cohort of survivors in whom treatment exposures and post-treatment outcomes have already been documented, the CCSS represents a valuable resource to support this work. Emmons et $\mathrm{al}^{57}$ successfully used the CCSS cohort to develop a clinically effective telephone intervention for smoking cessation, and other intervention trials are expected to be developed. Health interventions increasingly use telephone, internet, DVD, or other methods to make interventions deliverable to large groups of geographically dispersed participants, ${ }^{58,59}$ and these methods can be developed and tested quite efficiently by using the CCSS. Telephone interventions have already been developed for adult cancer survivors to reduce psychological distress and fatigue ${ }^{43-45}$ and to promote a variety of health behaviors, ${ }^{60,61}$ and these should be used as models for developing interventions for childhood cancer survivors. With more of these intervention studies in place, the CCSS will expand the current evidence-based interventions available for childhood cancer survivors and will demonstrate how they can be extended to the broader community and to a more diverse population of survivors. Ultimately, this research must answer the questions of where best to offer which supportive care interventions, and to whom, to definitively support implementation of and reimbursement for these intervention services.

\section{AUTHORS' DISCLOSURES OF POTENTIAL CONFLICTS OF INTEREST}

The author(s) indicated no potential conflicts of interest.

\section{AUTHOR CONTRIBUTIONS}

Manuscript writing: Lonnie K. Zeltzer, Christopher Recklitis, David Buchbinder, Bradley Zebrack, Jacqueline Casillas, Jennie C.I. Tsao, Qian Lu, Kevin Krull

\section{REFERENCES}

1. Parsons SK, Brown AP: Evaluation of quality of life of childhood cancer survivors: A methodologica conundrum. Med Pediatr Oncol 1:46-53, 1998 (suppl)

2. Zebrack BJ, Zeltzer LK: Quality of life issues and cancer survivorship. Curr Probl Cancer 27:198211, 2003

3. Recklitis CJ, Parsons SK, Shih MC, et al: Factor structure of the brief symptom inventory-18 in adult survivors of childhood cancer: Results from the childhood cancer survivor study. Psychol Assess 18:22-32, 2006

4. Derogatis LR: Brief Symptom Inventory (BSI): Administration, scoring, and procedures manual. Minneapolis, MN, NCS Pearson, 2000

5. Derogatis LR, Melisaratos $N$ : The Brief Symptom Inventory: An introductory report. Psychol Med 13:595-605, 1983

6. Ware JE Jr, Sherbourne CD: The MOS 36item short-form health survey (SF-36): Conceptual framework and item selection. Med Care 30:473483, 1992

7. Ware JE, Kosinski M, Gandek B: SF-36 Health Survey: Manual and Interpretation Guide. Lincoln, RI, Quality Metric Inc, 2003

8. Reulen RC, Zeegers MP, Jenkinson $C$, et al: The use of the SF-36 questionnaire in adult survivors of childhood cancer: Evaluation of data quality, score reliability, and scaling assumptions. Health Qual Life Outcomes 4:77, 2006

9. Cantril $\mathrm{H}$ : The Pattern of Human Concerns. New Brunswick, NJ, Rutgers University Press, 1965

10. Ashing-Giwa K, Ganz PA, Petersen L: Quality of life of African-American and white long term breast carcinoma survivors. Cancer 85:418-426, 1999

11. Ganz PA, Desmond KA, Leedham B, et al: Quality of life in long-term, disease-free survivors of breast cancer: A follow-up study. J Natl Cancer Inst 94:39-49, 2002

12. Krull KR, Gioia G, Ness KK, et al: Reliability and validity of the Childhood Cancer Survivor Study Neurocognitive Questionnaire. Cancer 113:21882197, 2008

13. Gioia GA, Isquith PK, Guy SC, et al: Behavior Rating Inventory of Executive Function. Odessa, FL, Psychological Assessment Resources Inc, 2000

14. Zill N, Peterson J: Behavior Problems Index Washington, DC, Child Trends Inc, 1986

15. Hudson MM, Mertens AC, Yasui $Y$, et al: Health status of adult long-term survivors of childhood cancer: A report from the Childhood Cancer Survivor Study. JAMA 290:1583-1592, 2003

16. Zeltzer LK, Lu Q, Leisenring W, et al: Psychosocial outcomes and health-related quality of life in adult childhood cancer survivors: A report from the childhood cancer survivor study. Cancer Epidemiol Biomarkers Prev 17:435-446, 2008

17. Thornton KE, Carmody DP: Electroencephalogram biofeedback for reading disability and traumatic brain injury. Child Adolesc Psychiatr Clin N Am 14:137-162, 2005

18. Schultz KA, Ness KK, Whitton J, et al: Behavioral and social outcomes in adolescent survivors of childhood cancer: A report from the childhood cancer survivor study. J Clin Oncol 25:3649-3656, 2007

19. Ness KK, Gurney JG, Zeltzer LK, et al: The impact of limitations in physical, executive, and emotional function on health-related quality of life among adult survivors of childhood cancer: A report from the Childhood Cancer Survivor Study. Arch Phys Med Rehabil 89:128-136, 2008

20. Zebrack BJ, Gurney JG, Oeffinger $K$, et al: Psychological outcomes in long-term survivors of childhood brain cancer: A report from the childhood cancer survivor study. J Clin Oncol 22:999-1006, 2004

21. Mulrooney DA, Ness KK, Neglia JP, et al: Fatigue and sleep disturbance in adult survivors of childhood cancer: A report from the childhood cancer survivor study (CCSS). Sleep 31:271-281, 2008

22. Nathan $P C$, Ness $K K$, Greenberg $M L$, et al: Health-related quality of life in adult survivors of childhood Wilms tumor or neuroblastoma: A report 
from the childhood cancer survivor study. Pediat Blood Cancer 49:704-715, 2007

23. Nagarajan $R$, Clohisy $D R$, Neglia JP, et al: Function and quality-of-life of survivors of pelvic and lower extremity osteosarcoma and Ewing's sarcoma: The Childhood Cancer Survivor Study. Br J Cancer 91:1858-1865, 2004

24. Zebrack BJ, Zeltzer LK, Whitton J, et al Psychological outcomes in long-term survivors of childhood leukemia, Hodgkin's disease, and nonHodgkin's lymphoma: A report from the Childhood Cancer Survivor Study. Pediatrics 110:42-52, 2002

25. Sugarbaker PH, Barofsky I, Rosenberg SA, et al: Quality of life assessment of patients in extremity sarcoma clinical trials. Surgery 91:17-23, 1982

26. Moleski M: Neuropsychological, neuroanatomical, and neurophysiological consequences of CNS chemotherapy for acute lymphoblastic leukemia. Arch Clin Neuropsychol 15:603-630, 2000

27. Campbell LK, Scaduto M, Sharp $W$, et al: A meta-analysis of the neurocognitive sequelae of treatment for childhood acute lymphocytic leukemia. Pediatr Blood Cancer 49:65-73, 2007

28. Krull KR, Okcu MF, Potter B, et al: Screening for neurocognitive impairment in pediatric cancer long-term survivors. J Clin Oncol 26:4138-4143, 2008

29. Roth RM, Isquith PK, Gioia GA: Behavior Rating Inventory of Executive Function: Adult Version. Lutz, FL, Psychological Assessment Resources Inc, 2005

30. Emmons KM, Butterfield RM, Puleo E, et al: Smoking among participants in the childhood cancer survivors cohort: The Partnership for Health Study. J Clin Oncol 21:189-196, 2003

31. Lown EA, Goldsby $R$, Mertens $A C$, et al: Alcohol consumption patterns and risk factors among childhood cancer survivors compared to siblings and general population peers. Addiction 103: 1139-1148, 2008

32. Greenfield TK, Nayak MB, Bond J, et al: Maximum quantity consumed and alcohol-related problems: Assessing the most alcohol drunk with two measures. Alcohol Clin Exp Res 30:1576-1582 2006

33. Holland JC, Kash KM, Passik S, et al: A brief spiritual beliefs inventory for use in quality of life research in life-threatening illness. Psychooncology 7:460-469, 1998

34. Meadows AT, Black B, Nesbit ME Jr, et al: Long-term survival: Clinical care, research, and education. Cancer 71:3213-3215, 1993

35. Zebrack BJ, Chesler M: Health-related worries, self-image, and life outlooks of long-term survivors of childhood cancer. Health Soc Work 26:245-256, 2001

36. Zeltzer LK: Cancer in adolescents and young adults psychosocial aspects: Long-term survivors. Cancer 71:3463-3468, 1993

37. Stanton AL: Psychosocial concerns and interventions for cancer survivors. J Clin Oncol 24:51325137, 2006

38. Kornblith AB, Herndon JE 2nd, Zuckerman E, et al: Comparison of psychosocial adaptation of advanced stage Hodgkin's disease and acute leukemia survivors: Cancer and Leukemia Group B. Ann Oncol 9:297-306, 1998

39. McCorkle R, Tang ST, Greenwald $H$, et al: Factors related to depressive symptoms among long-term survivors of cervical cancer. Health Care Women Int 27:45-58, 2006

40. Cella D, Bullinger M, Scott $C$, et al: Group vs individual approaches to understanding the clinical significance of differences or changes in quality of life. Mayo Clin Proc 77:384-392, 2002

41. Kazak AE, Simms S, Alderfer MA, et al: Feasibility and preliminary outcomes from a pilot study of a brief psychological intervention for families of children newly diagnosed with cancer. J Pediatr Psychol 30:644-655, 2005

42. Scheier MF, Helgeson VS, Schulz R, et al: Interventions to enhance physical and psychological functioning among younger women who are ending nonhormonal adjuvant treatment for early-stage breast cancer. J Clin Oncol 23:4298-4311, 2005

43. Marcus AC, Garrett KM, Cella D, et al: Telephone counseling of breast cancer patients after treatment: A description of a randomized clinical trial. Psychooncology 7:470-482, 1998

44. Donnelly JM, Kornblith AB, Fleishman S, et al: A pilot study of interpersonal psychotherapy by telephone with cancer patients and their partners. Psychooncology 9:44-56, 2000

45. Pinto BM, Frierson GM, Rabin C, et al: Homebased physical activity intervention for breast cancer patients. J Clin Oncol 23:3577-3587, 2005

46. Cramp F, Daniel J: Exercise for the management of cancer-related fatigue in adults. Cochrane Database Syst Rev: CD006145, 2008

47. Pizzo PA, Poplack DG: Principles and Practice of Pediatric Oncology. Philadelphia, PA, Lippincott, Williams, \& Wilkins, 2006

48. Doorenbos A, Given B, Given C, et al: Reducing symptom limitations: A cognitive behavioral intervention randomized trial. Psychooncology 14 574-584, 2005

49. Cimprich B, Janz NK, Northouse $L$, et al: Taking CHARGE: A self-management program for women following breast cancer treatment. Psychooncology 14:704-717, 2005

50. Rosal MC, Olendzki B, Reed GW, et al: Diabetes self-management among low-income Spanishspeaking patients: A pilot study. Ann Behav Med 29:225-235, 2005

51. Linton SJ, Boersma $K$, Jansson $M$, et al: The effects of cognitive-behavioral and physical therapy preventive interventions on pain-related sick leave: A randomized controlled trial. Clin J Pain 21:109 119, 2005

52. Mulhern RK, Merchant TE, Gajjar A, et al: Late neurocognitive sequelae in survivors of brain tumours in childhood. Lancet Oncol 5:399-408, 2004

53. Mulhern RK, Butler RW: Neurocognitive sequelae of childhood cancers and their treatment. Pediatr Rehabil 7:1-14, 2004; discussion 15-16

54. Worchel-Prevatt F, Heffer RW, Prevatt B, et al: A school reentry program for chronically ill children. J Sch Psychol 36:261-279, 1998

55. Prevatt FA, Heffer RW, Lowe TA: A review of school reintegration programs for children with cancer. J Sch Psychol 38:447-467, 2000

56. Butler RW, Copeland DR, Fairclough DL, et al: A multicenter, randomized clinical trial of a cognitive remediation program for childhood survivors of a pediatric malignancy. J Consult Clin Psychol 76:367 378, 2008

57. Emmons KM, Puleo $E$, Park $E$, et al: Peerdelivered smoking counseling for childhood cancer survivors increases rate of cessation: The partnership for health study. J Clin Oncol 23:6516-6523, 2005

58. Schofield $P$, Jefford $M$, Carey $M$, et al: Preparing patients for threatening medical treatments: Effects of a chemotherapy educational DVD on anxiety, unmet needs, and self-efficacy. Support Care Cancer 16:37-45, 2008

59. Ito KE, Kalyanaraman S, Ford CA, et al: Let's Talk About Sex: Pilot study of an interactive CDROM to prevent HIV/STIS in female adolescents. AIDS Educ Prev 20:78-89, 2008

60. Parsons JK, Newman V, Mohler JL, et al: The Men's Eating and Living (MEAL) study: A Cancer and Leukemia Group B pilot trial of dietary intervention for the treatment of prostate cancer. Urology 72:633-637, 2008

61. Stanton AL, Ganz PA, Kwan L, et al: Outcomes from the Moving Beyond Cancer psychoeducational, randomized, controlled trial with breast cancer patients. J Clin Oncol 23:60096018, 2005 